\title{
Seawall effects in a coastal wetland landscape: spatial changes in soil carbon and nitrogen pools
}

\author{
Shiwei Zhou ${ }^{1} \cdot$ Xiaoli Bi $^{2}$ (I) \\ Received: 12 May 2019 / Revised: 4 July 2019 / Accepted: 4 December 2019 / Published online: 12 February 2020 \\ (C) Springer Nature B.V. 2020
}

\begin{abstract}
Seawalls are common features in coastal landscapes. They can alter ecological processes in coastal wetland ecosystems at multiple scales. Evaluation those ecological effects requires consideration of spatial characteristics of variables. We used a scaling method, quadrat variance analysis, to quantify the patterns and scale characteristics of soil organic carbon (SOC) and total nitrogen (TN) in a wetland reclaimed by a 30-year-old seawall and a natural wetland in the Yellow River Delta, China, and then analyzed their spatial relationships with different plant and soil variables. The results revealed that spatial variances in SOC and $\mathrm{TN}$ in the seawall-reclaimed wetland had two scales. The smaller scale $(40 \mathrm{~m})$ was the distance between soil salinity patches, reflecting the influences of soil salinity on SOC and TN. The larger one $(130 \mathrm{~m})$ was the distance between shrub communities and the grass patches beneath them, reflecting the influences of shrubs on SOC and TN. However, in the natural wetland, both SOC and TN had only one scale of variance $(90 \mathrm{~m})$, which reflected the influences of soil salinity. Soil salinity determined the spatial patterns of dominant grass patches, and thus SOC and TN. Seawall altered plant distributions and shrub-grass interactions, thereby affected the patterns of SOC and TN. Scaling method can help us to efficiently evaluate the landscape impacts of seawalls on coastal wetlands.
\end{abstract}

Keywords Spatial pattern $\cdot$ Scaling method $\cdot$ Soil organic carbon $\cdot$ Coastal wetland $\cdot$ The Yellow River Delta

\section{Introduction}

Coastal wetlands sequester blue carbon over both the short term in plant biomass and the longer term in sediments (Duarte et al. 2005), contributing greatly to global carbon storage (Lo Iacono et al. 2008). In addition to their huge sizes, soil carbon pools in coastal wetlands have higher spatial heterogeneity than those in dry inland ecosystems, such as farmland and grassland ecosystems, due to dynamic sea-land interactions (Chen et al. 2013). This presents additional challenges for monitoring, assessing, and predicting soil nutrient budgets in coastal wetland ecosystems (Ettema and Wardle 2002).

Many factors can potentially influence the spatial patterns of soil nutrients in coastal wetland ecosystems. These factors may respond differently to changes in coastal wetland

Xiaoli Bi

xlbi@yic.ac.cn

1 School of Agriculture, Ludong University, Yantai, Shandong, China

2 Yantai Institute of Coastal Zone Research, Chinese Academy of Sciences, Yantai, Shandong, China ecosystems at local, regional and global scales (Wang et al. 2017). Therefore, understanding the relationships between soil nutrients and environmental variables at different scales is helpful for explaining the mechanisms of heterogeneity of soil nutrient storage in coastal ecosystems.

Coastal wetlands have been rapidly disturbed by human activities. Seawalls are common structures to protect coastal zones from erosion and tidal storms (Davis et al. 1982). Seawalls can alter the environmental backgrounds, landscape characteristics, and ecological processes of the original coastal ecosystems (Rosenzweig et al. 2011; Perkol-Finkel et al. 2012). Recent research has indicated that seawalls can provide vertical habitats for many intertidal or subtidal species (Bulleri and Chapman 2010). Seawalls can also play important roles in controlling species invasion (Yang et al. 2017). Previous works focused on the local effects of seawalls on seawater environments and intertidal wetland ecosystems, but few have considered the effects of seawalls at landscape scales.

In China, the seawalls along $\sim 60 \%$ of the total coastline have dramatically altered coastal wetland ecosystems (Ma et al. 2014). These seawalls, which have reclaimed coastal wetlands, have increased in length by 3.4 times over the past two decades, reaching $11,000 \mathrm{~km}$ in 2010 . From 1950 to 
2000 , seawall-reclaimed wetland areas increased by an average of 24,000 ha year $^{-1}$, resulting in the loss of $50 \%$ of the natural coastal wetlands (Earth Science Division Consultation Group, Chinese Academy of Sciences 2011). Currently, environmental impact assessments for coastal wetland reclamation projects are mainly focused on the potential losses of fisheries, environmental pollution, and other direct impacts on the ecosystem. Alteration of wetland vegetation can amplify the spatial heterogeneity of soil variables, making it difficult to explain the consequent ecological processes, especially in wetlands undergoing substantial vegetation changes with distinct shifts in dominance or functional type (Xia et al. 2016).

Spatial variations in soil and plant variables in disturbed ecosystems can provide insight on ecological processes across different spatial scales (Craine et al. 2009). Scaling methods are the most precise way to quantify cross-scale characteristics of typical ecosystems and can effectively explain ecological processes that occur at different scales (Wu 2004). The issue of scaling influences every aspect of landscape ecology and management (Urban 2005). The development of geographical information system (GIS) technology has made it possible to analyze scale when studying complex ecological processes (Liu et al. 2010).

The main objectives of this study were to (1) compare spatial patterns of soil organic carbon (SOC) and total nitrogen (TN) in a 30-year-old seawall-reclaimed wetland and an adjacent natural wetland; (2) quantify the spatial scales of SOC and TN; and (3) analyze the main biological and environmental variables that potentially influence the patterns of SOC and $\mathrm{TN}$ in both wetland types. We hypothesized that seawalls can change the patterns and scales of SOC and TN, and that the related variables have spatial patterns and scales similar to those of SOC and TN.

\section{Study area and methods}

\section{Study area}

The study area is located in the Yellow River Delta (YRD), China, on the southwest coast of the Bohai Sea (Fig. 1). Due to economic development, land cover in this area has changed dramatically in recent decades (Ottinger et al. 2013). Since the 1980s, approximately $658.6 \mathrm{~km}$ of seawalls were built along the coastline of this delta to protect Dongying City and its great oil fields from natural disasters such as storm tides and erosion (Fu et al. 2011). After the seawall construction, plant species began to encroach on the tidal flats, leading to changes in vegetation types.

The YRD experiences a warm temperate climate with distinct seasons. The annual mean temperature is $12.1^{\circ} \mathrm{C}$, and annual mean rainfall and evaporation are 551.6 and $1962 \mathrm{~mm}$, respectively. Tidal fluctuation is mixed semidiurnal, with successive tides of unequal size (He et al. 2009). The altitude of this region is low, and most parts are $<10 \mathrm{~m}$ in elevation. The main soil type is Gleyic Solonchak and the soil texture is mainly sandy loam (Yu et al. 2014).

\section{Sample designation}

Field investigations were conducted in May and September of 2015. To quantify the spatial distributions of soil and plant variables along the sea-land gradient, two transects were designed in (a) a regenerated wetland after seawall reclamation in 1980 at Zhuangxi, where the seawall has the ability to stop a 50-year flood, and (b) the adjacent natural salt marsh in the Yiqian'er Nature Reserve, where the wetland is occasionally flooded by large tides (Fig. 1).

The transect lengths were $500 \mathrm{~m}$ and $400 \mathrm{~m}$ in the reclaimed and natural wetlands, respectively. Samples were designated at 5-m intervals using a global positioning system device (GPSMAP 62sc; Garmin, Taiwan, China). In total, there were 100 and 80 sample sites from the seawallreclaimed and natural wetlands, respectively (Fig. 1).

At each site, two soil cores $(15 \mathrm{~cm}$ depth and $2 \mathrm{~cm}$ diameter) were collected: one for soil salinity, SOC, TN, and another for root biomass. There are no tree species in this region, so only shrub and grass species were recorded in the plant investigation. Numbers and crown widths of shrub species (only Tamarix chinensis) within a 2-m wide belt centered on the transect lines were recorded (Liu et al. 2010). The percentage cover of grass species within a $0.5 \times 0.5-\mathrm{m}$ plot at each sample site was recorded. Above-ground biomass, including green grass biomass and litter mass, were collected at each site and then oven-dried for at least $72 \mathrm{~h}$ at $60^{\circ} \mathrm{C}$ to determine dry weight.

\section{Laboratory analyses}

Soil samples were air-dried and crushed. Roots and gravel were removed and then the soil samples were passed through a 2-mm sieve. Electrical conductivity, as the standard indicator of soil salinity, was measured using a conductivity meter (TP320; TP320; Mitong, Beijing, China). SOC and TN were measured using an elemental analyzer (vario MACRO cube; Elementar, Langenselbold, Germany). Roots were obtained by washing the soil cores and then dried for at least $72 \mathrm{~h}$ at $60{ }^{\circ} \mathrm{C}$ to determine dry weight.

\section{Statistical methods}

One-way analysis of variance (ANOVA) was used to compare differences in soil and plant variables between the seawallreclaimed and natural wetlands using SAS version 9.2 (SAS Institute, Cary, NC, USA). Quadrat variance methods were used to assess the spatial scales of those variables. Through 
calculating the variance of differences among blocks of different sizes, the patterns of variance can be determined and used to detect the scale. There is a series of similar quadrat methods (Liu et al. 2010); here, we choose three-term local quadrat variance (3TLQV) because it is less sensitive to trends in data and has less peak drift (Liu et al. 2010). Cross-Mantel tests were used to test for spatial cross-correlations between SOC and TN with soil and plant variables. Both 3TLQV and the Mantel test were processed using PASSaGE version 2 (Rosenberg and Anderson 2011).

\section{Results}

\section{Changes in carbon and nitrogen along the sea-land gradient}

The ANOVA results revealed significant differences in soil and plant variables between seawall-reclaimed and natural wetlands. The mean soil SOC, TN, and salinity were significantly lower in the seawall-reclaimed wetland, while the mean carbon:nitrogen $(\mathrm{C}: \mathrm{N})$ ratio were significantly higher compared to the natural wetland (Table 1).

The average crown width of shrubs was significantly higher in the seawall-reclaimed wetland than in the natural wetland. Grass variables in the seawall-reclaimed wetland also differed from those in the natural wetland. Phragmites communis was the dominant grass species in the seawallreclaimed wetland, while Suaeda glauca was dominant in the natural wetland. The average percentage grass cover and above-ground biomass were insignificantly lower in the seawall-reclaimed wetland compared to the natural wetland (Table 1). Along the sea-land gradient, soil variables such as SOC, TN, salinity, and C:N ratio showed similar patterns in both wetlands (Fig. 2).

\section{Spatial scale variation}

Quadrat variance methods revealed two spatial scales for soil SOC, TN, salinity, shrub variables, grass variables, and biomass of approximately $20-40 \mathrm{~m}$ and $130-150 \mathrm{~m}$ in the seawall-reclaimed wetland (Fig. 3, Table 2).

In the natural wetland, soil salinity, shrub variables, total grass cover, $P$. communis cover, and biomass variables had two smaller scales of $20-30 \mathrm{~m}$ and $90-120 \mathrm{~m}$, while SOC and TN had one obvious scale of $90 \mathrm{~m}$ (Fig. 5, Table 2). The dominant grass species, $S$. glauca, had one scale of $10 \mathrm{~m}$ (Table 2).

\section{Relationships between SOC and TN with soil and plant variables}

Cross-correlation revealed significant spatial correlations in seawall-reclaimed wetland between SOC with the number of shrubs, shrub crown width, percentage $P$. communis cover, total grass cover, above-ground and root biomass, soil C:N, and soil salinity. Significant spatial correlations were also revealed between TN with percentage $P$. communis cover, above-ground biomass, and soil C:N (Table 3).
Fig. 1 Study area and sample design




Table 1 ANOVA results of plant and soil variables in seawallreclaimed and natural wetlands

\begin{tabular}{|c|c|c|c|c|c|}
\hline & \multicolumn{2}{|c|}{ Seawall-reclaimed wetland } & \multicolumn{2}{|c|}{ Natural wetland } & \multirow[t]{2}{*}{$P$} \\
\hline & Mean & S.E. & Mean & S.E. & \\
\hline Number of shrubs per meter & 0.0950 & 0.0745 & 0.1100 & 0.0939 & 0.0637 \\
\hline Shrub crown width (m) & 0.4220 & 0.0505 & 0.3925 & 0.0573 & 0.1892 \\
\hline Phragmites communis cover $(\%)$ & 23.1000 & 3.6061 & 11.7500 & 2.9861 & $0.0201^{*}$ \\
\hline Suaeda glauca cover (\%) & 11.3000 & 2.5885 & 27.5000 & 4.2378 & $0.0008^{*}$ \\
\hline Total cover $(\%)$ & 34.4000 & 4.2719 & 39.2500 & 4.9002 & 0.4553 \\
\hline Above-ground biomass $\left(\mathrm{g} \mathrm{m}^{-2}\right)$ & 414.5555 & 54.5088 & 451.7555 & 62.6855 & 0.6538 \\
\hline Root biomass $\left(\mathrm{g} \mathrm{m}^{-2}\right)$ & 122.2134 & 22.1337 & 196.3376 & 28.5031 & $0.0383^{*}$ \\
\hline Soil TN (\%) & 0.0571 & 0.0017 & 0.0651 & 0.0020 & $0.0237^{*}$ \\
\hline Soil SOC (\%) & 1.3706 & 0.0146 & 1.4621 & 0.0225 & $0.0005^{*}$ \\
\hline Soil C:N & 25.6402 & 0.5859 & 23.9470 & 0.3958 & $0.0024^{*}$ \\
\hline Soil salinity (mS) & 3.4759 & 0.1534 & 4.2534 & 0.1998 & $0.0020^{*}$ \\
\hline Elevation (m) & -1.5386 & 0.3565 & 1.8098 & 0.1436 & $0.0000^{*}$ \\
\hline
\end{tabular}

* Significant difference at $P<0.05$

Although the variables influencing SOC and TN in the seawall-reclaimed wetland were quite different, the variables that potentially influenced SOC and TN in the natural wetland were quite similar. That is, percentage $P$. communis cover, total grass cover, soil C:N, and soil salinity were significantly related to both SOC and TN in the natural wetland (Table 3).

\section{Discussion}

\section{Changes in soil variables along the sea-land gradient}

In the YRD, the natural vegetation along the sea-land gradient is usually dominated by S. glauca, followed by $P$. communis
Fig. 2 Soil variables along the transects. Red line: seawallreclaimed wetland; green line: natural wetland
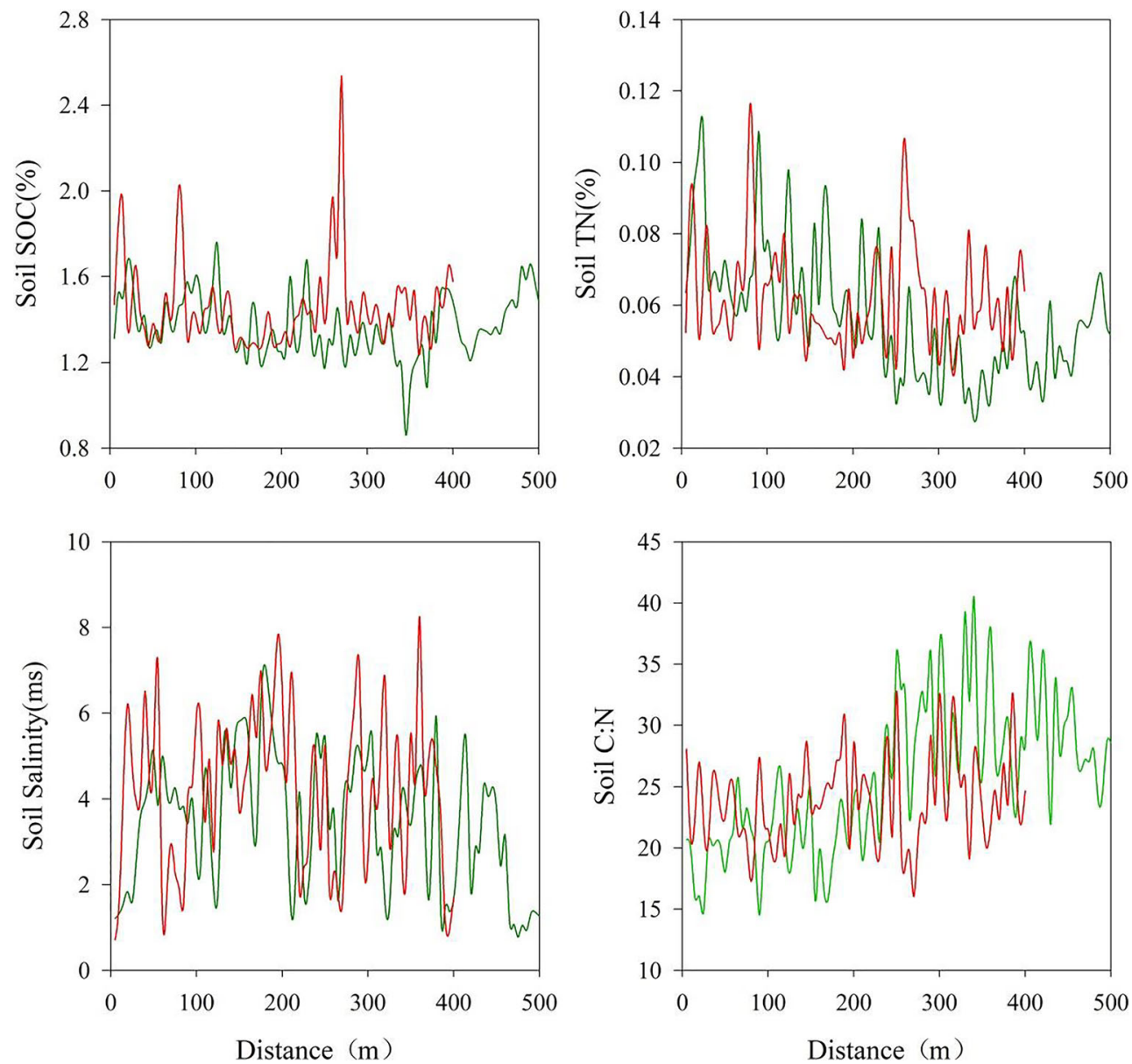
and the shrub T. chinensis. Seawall reclamation accelerated the positive community succession in the intertidal zone and consequently changed the gradient pattern. Shrub $T$. chinensis has been encroached into the grassland and $P$. communis became the dominant grass species, replacing $S$. glauca (Bi et al. 2014). The shift in the plant community could affect the chemical and physical characteristics of soil layers, and thus the nutrient cycling processes, by altering primary production, litter, root biomass, and microclimates.

The basic driving factor for plant changes after seawall reclamation is the change in soil salinity. Soil salinity is a critical factor that not only controls the patterns of intertidal wetland vegetation, but also increases rates of net nitrogen and phosphorus mineralization fluxes and turnover in tidal wetland soils, resulting in alteration of the soil nutrient content and distribution (Yu et al. 2016). We observed significant decreases in soil salinity in the seawall-reclaimed wetland (Table 1), because the seawall effectively prevented regular tidal activities, causing the saline marsh to directly develop toward a fresh wetland. The crown widths of $T$. chinensis were significantly larger than in the natural wetland, indicating that the shrub grew better in the low-saline mesophytic environment. As a result, the salinity-induced changes in plant community structure could lead to changes in soil nutrients.

Both soil SOC and TN decreased significantly in the seawall-reclaimed wetland, reflecting the lower ground primary production and root biomass (Table 1). Two reasons can explain these changes. First, as a relatively dry environment, reclaimed wetland has lower production acclamation and turnover rates than natural intertidal wetland (Duarte et al. 2005). The lower root biomass in seawall-reclaimed wetland is indicative of lower carbon and nitrogen inputs (Table 1). In addition, natural marsh has the potential to contribute substantially to long-term carbon sequestration resulting from the higher rate of organic carbon sequestration in wetland sediments (McLeod et al. 2011). Second, the shrub crown widths in seawall-reclaimed wetland were significantly larger than in the natural wetland, suggesting that the soils in the woody plant patches may have higher SOC, TN, and root biomass than in grass patches due to the "fertile island" effects of shrubs. Actually, soil SOC and TN contents under shrub patches in the seawall-reclaimed wetland were $0.062 \%$ and $1.461 \%$, respectively, significantly higher than the contents under shrub patches in the natural wetland of $0.053 \%$ and $1.304 \%$. However, the average SOC and TN along the transect were lower in seawall-reclaimed wetland than in natural wetland (Table 1), which may contribute to the higher spatial heterogeneity of vegetation in the seawall-reclaimed wetland. Habitat fragmentation in seawall-reclaimed wetland may weaken mean values of soil SOC and TN. These results also demonstrated the importance of quantifying spatial patterns of soil properties and patchy vegetation.
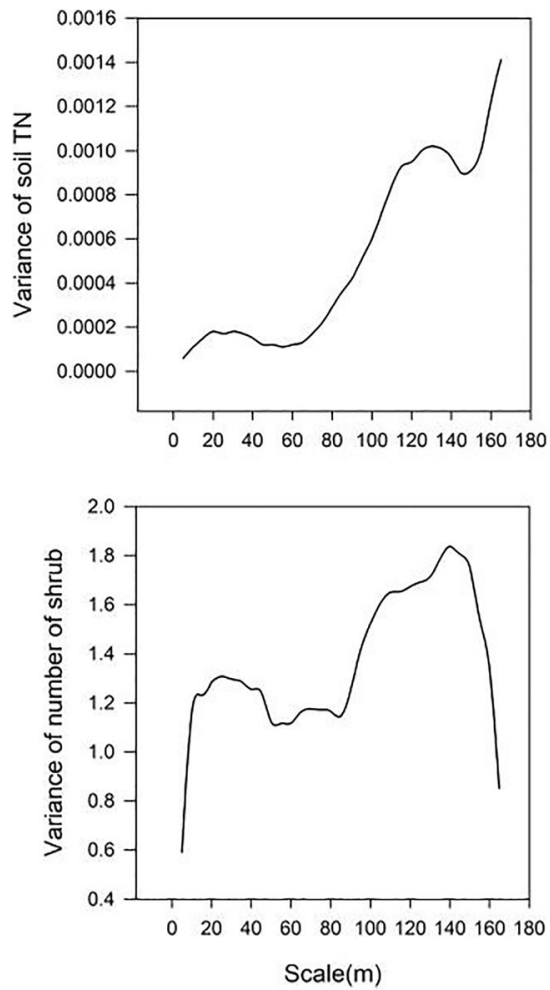


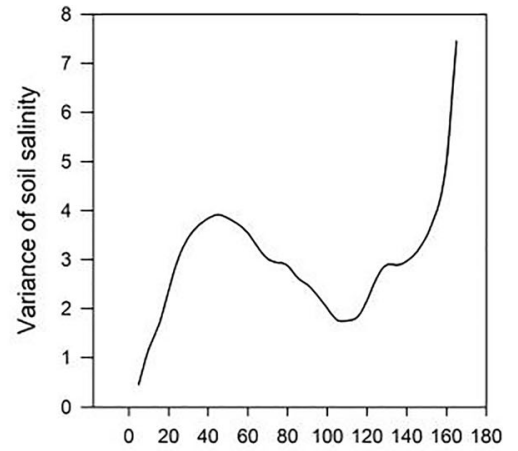

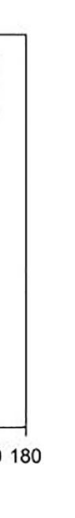

Fig. 3 Scale variances of plant and soil variables in seawall-reclaimed wetland 


\section{Spatial scale variations of SOC and TN}

Landscape patterns and ecological processes usually occur across multiple scales, and their relationships are often scaledependent (Levin 1992). In our study, the scaling characteristics of soil and plant variables in seawall-reclaimed and natural wetlands were quite different, indicative of different processes of SOC and TN in the two wetland types.

All variables in the seawall-reclaimed wetland had two obvious scales (Table 2). The consistency of the scale characteristics of those variables can improve our understanding of soil, plants, and soil-plant interactions and how they influence the spatial patterns of SOC and TN. The smaller scale $(45 \mathrm{~m})$ was the approximate distance from the center of one soil salinity patch to another, representing the major influence of soil salinity on grass species and individual shrubs. The larger scale $(130 \mathrm{~m})$ was the approximate distance from the center of one shrub community to another, representing the influence of shrub aggregation (Fig. 4). We can conclude that soil salinity affected SOC and TN patterns at a smaller scale, while shrub communities affected their patterns at a larger scale.

It is easy to understand the influence of soil salinity at the smaller scale. When the scale is enlarged, the influence of soil salinity is weakened, while the influence of shrubs becomes stronger due to the formation of larger shrub communities (Fig. 5). Changes in the salt and hydrologic conditions promoted the growth of shrub species in this wetland, similar to cases of shrub encroachment in other coastal wetlands (Saintilan and Rogers 2015). Shrubs are known to function as fertile islands, altering the spatial patterns of grass species distribution and abundance (Liu et al. 2017). For both P. communis and S. glauca, percentage cover and biomass variables showed similar scale variances, possibly attributable to changes in strategies due to the encroaching shrubs (He et al. 2012). Those larger scale shrub-induced changes in the ground layer could potentially influence the magnitude of soil SOC. In our study, the effects of shrubs might be more than simple island effects, resulting in grass species aggregation at a larger scale, and influencing the magnitude and patterns of soil SOC, and to a lesser extent, soil TN.

SOC and TN in the natural wetland had one scale, consistent with the larger scale of soil salinity $(90 \mathrm{~m})$. This indicates that larger patterns of soil salinity primarily determined the SOC and TN patterns, while shrub species had little influence on SOC and $\mathrm{TN}$ in the natural wetland. Soil salinity and the grass species $P$. communis determined the SOC and TN patterns. In contrast to seawall-reclaimed wetland, $S$. glauca had one scale $(10 \mathrm{~m})$ in the natural wetland, reflecting the randomly distributed characteristic of natural S. glauca patches. This confirms our hypothesis that the seawall changed not only the patterns of dominant plant species, but also the patterns of soil SOC and TN according to the increased spatial heterogeneity of the plants.

Soil salinity in the natural wetland had two scales of variance $(20 \mathrm{~m}$ and $90 \mathrm{~m})$, which became larger in the seawallreclaimed wetland $(40 \mathrm{~m}$ and $150 \mathrm{~m}$ ), although the mean salinity was decreased in the reclaimed wetland. This is possibly because the seawall changed not only the accumulation of soil salt, but also the hydrological process. The collective influences of salt and water are reflected clearly at the larger scale, and thus played more important roles than at a smaller scale. The changes in patterns of salt and water lead to changes in patterns of grass and shrub species, and thus grass-shrub interactions, and finally SOC and TN.

Anthropogenic activities have greatly altered the original distributions of nutrients in coastal wetlands. We can easily monitor changes in plant patterns after seawall reclamation using remote sensing technologies, but it is difficult to monitor changes in soil and roots. Scaling methods provide new insights for quantifying these spatial changes in underground systems, and will be useful tools in practical applications for
Table 2 Spatial scales of plant and soil variables in seawallreclaimed and natural wetlands

\begin{tabular}{lll}
\hline & \multicolumn{2}{l}{ Scales (m) } \\
\cline { 2 - 3 } & Seawall-reclaimed wetland & Natural wetland \\
\hline Number of shrubs & 30,130 & 15,105 \\
Shrub crown width & 30,135 & 15,105 \\
Phragmites communis cover (\%) & 40,130 & 20,90 \\
Suaeda glauca cover (\%) & 45,140 & 10 \\
Grass cover (\%) & 40,140 & 20,90 \\
Above-ground biomass & 35,140 & 10,120 \\
Root biomass & 40,130 & 20,105 \\
Soil SOC & 40,130 & 90 \\
Soil TN & 30,130 & 90 \\
Soil salinity & 45,130 & 20,90
\end{tabular}


Table 3 Cross-Mantel results between SOC and TN with plant and soil variables in seawall-reclaimed and natural wetlands

\begin{tabular}{|c|c|c|c|c|c|c|c|c|}
\hline & \multicolumn{4}{|c|}{ Seawall-reclaimed wetland } & \multicolumn{4}{|c|}{ Natural wetland } \\
\hline & \multicolumn{2}{|l|}{ SOC } & \multicolumn{2}{|l|}{$\mathrm{TN}$} & \multicolumn{2}{|l|}{ SOC } & \multicolumn{2}{|l|}{$\mathrm{TN}$} \\
\hline & $\mathrm{r}$ & $\mathrm{P}$ & $\mathrm{r}$ & $\mathrm{P}$ & $\mathrm{r}$ & $\mathrm{P}$ & $\mathrm{r}$ & $\mathrm{P}$ \\
\hline Number of shrubs per meter & 0.1748 & 0.0086 & 0.1004 & ns & -0.0949 & ns & -0.02282 & ns \\
\hline Shrub crown width (m) & 0.2355 & 0.0004 & 0.0271 & ns & -0.1069 & ns & -0.06215 & ns \\
\hline Phragmites communis cover $(\%)$ & 0.4147 & 0.0000 & 0.1822 & 0.00031 & 0.4819 & 0.0000 & 0.50304 & 0.0000 \\
\hline Suaeda glauca cover $(\%)$ & 0.0121 & ns & -0.0468 & ns & -0.0551 & ns & -0.03764 & ns \\
\hline Total cover $(\%)$ & 0.2719 & 0.0000 & 0.0604 & ns & 0.1410 & 0.0008 & 0.13807 & 0.0009 \\
\hline Above-ground biomass $\left(\mathrm{g} \mathrm{m}^{-2}\right)$ & 0.2459 & 0.0000 & 0.1758 & 0.0005 & 0.0227 & ns & 0.00983 & ns \\
\hline Root biomass $\left(\mathrm{g} \mathrm{m}^{-2}\right)$ & 0.1315 & 0.0402 & 0.1065 & ns & 0.1792 & 0.0402 & 0.18532 & 0.0305 \\
\hline Soil C:N & 0.1033 & 0.0232 & 0.7501 & 0.0000 & 0.2586 & 0.0002 & 0.59016 & 0.0000 \\
\hline Soil salinity (mS) & 0.2934 & 0.0000 & -0.0011 & $\mathrm{~ns}$ & 0.2789 & 0.0000 & 0.19443 & 0.0007 \\
\hline Elevation (m) & -0.0147 & ns & -0.0675 & ns & -0.0083 & ns & -0.02675 & ns \\
\hline
\end{tabular}

r, Mantel's r; $P$, significance level; ns, not significant $(P>0.05)$

monitoring coastal wetland degradation and wetland management in the future.

\section{Relationships between SOC and TN and other soil and plant variables}

The strong correlations between SOC and percentage P. communis cover, total grass cover, root biomass, soil C:N, and soil salinity in both the reclaimed and natural wetlands are consistent with the notion that grass cover, root production, soil C:N, and soil salinity may strongly influence SOC in this region (Bai et al. 2013; Wang et al. 2011). In addition, more attention should be paid to the close correlations between SOC and shrub variables in the seawall-reclaimed wetland, which are indicative of the importance of shrubs in determining the soil status and nutrition after seawall reclamation (Tables 2 and 3). Seawalls can promote the growth of shrub species by generating a relatively dry habitat; therefore, the
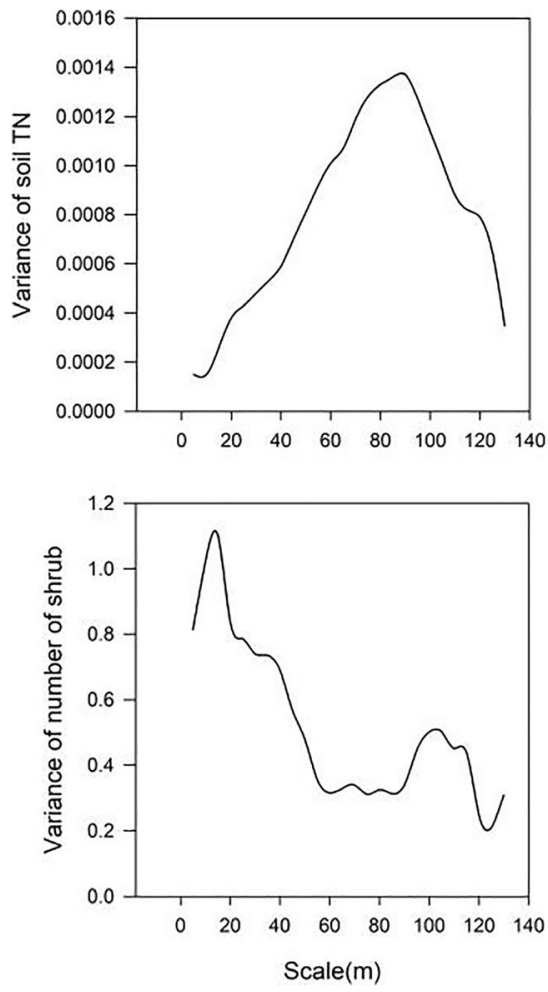
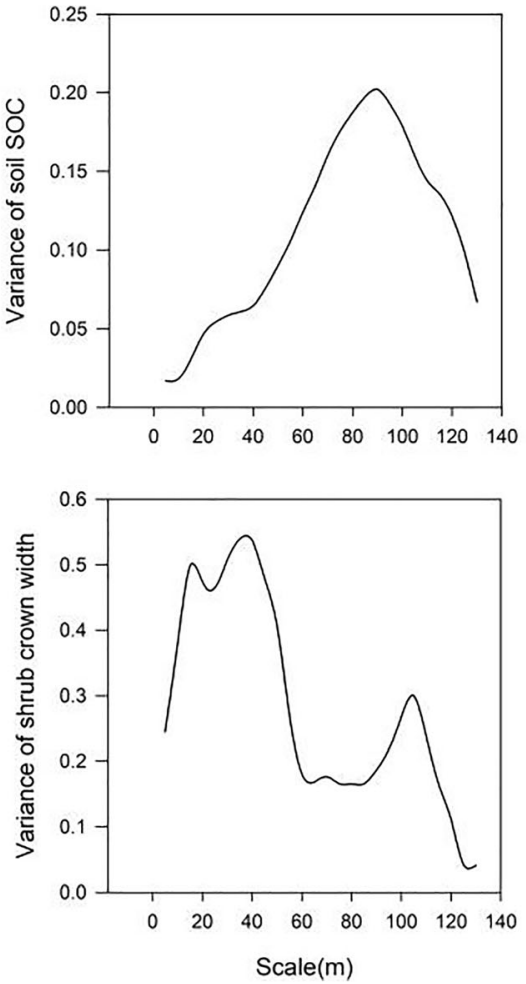
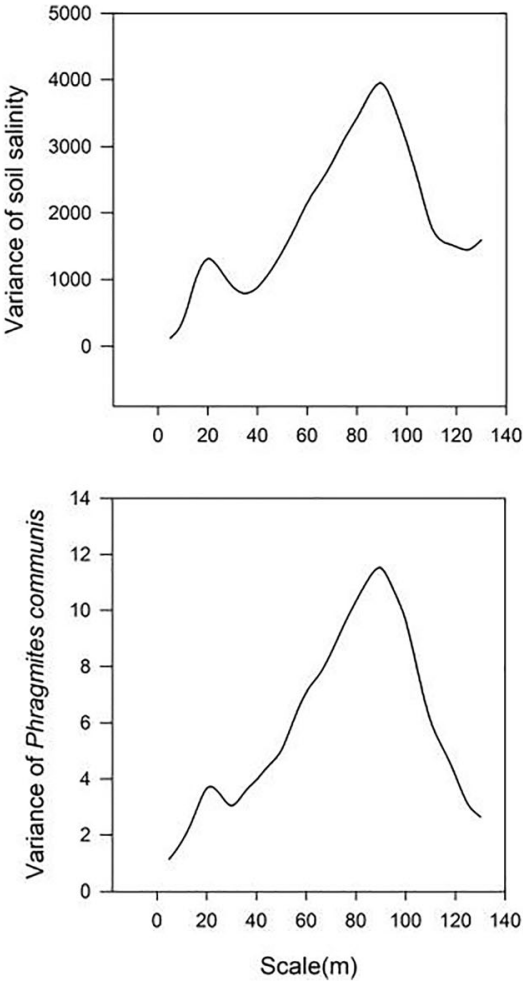

Fig. 4 Scale variances of plant and soil variables in natural wetland 
Fig. 5 Hypothesis for pattern changes in soil SOC from single shrubs to shrub clusters after seawall reclamation

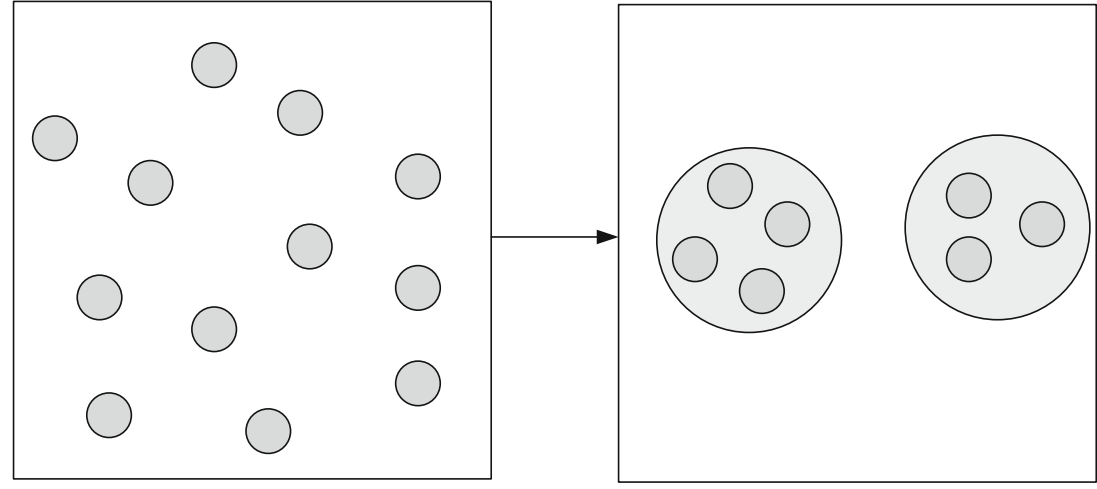

shrub crown width in seawall-reclaimed wetland was larger than in natural wetland (Table 1). It is widely accepted that shifts from grass to woody shrub dominance in drylands are followed by reduction of root biomass in surface soil (hence reduction of carbon and nitrogen inputs) due to the sparse, coarse, and deep root systems of shrub species (Liu et al. 2010). This may somewhat explain the lower SOC and TN contents in seawall-reclaimed wetland compared to natural wetland.

In seawall-reclaimed wetland, only percentage cover of P. communis and above-ground biomass were closely related to $\mathrm{TN}$, which also indicates the importance of grass species, especially $P$. communis, on soil nitrogen dynamics. At the same time, shrubs showed different relationships with SOC and TN, indicating a lesser influence of shrubs on TN in this wetland. Our work focused on changes in soil properties of topsoil, but we do not know how the relationship might change in deeper portions of the soil profile.

The factors closely related to SOC and TN in the natural wetland were similar, which was consistent with previous reports that SOC and TN exhibited similar changing tendencies along the sea-land gradient ( $\mathrm{Lu}$ et al. 2018). However, SOC and TN in the seawall-reclaimed wetland were quite different, which may also indicate that mechanisms of seawall-induced influence may differ for SOC and TN. The succession of SOC in seawall-reclaimed wetland might be more complex than that of TN; further study is needed.

\section{Conclusion}

In this study, we used spatial statistics methods to quantify the pattern and scale characteristics of soil organic carbon (SOC) and total nitrogen $(\mathrm{TN})$ along the sea-land gradients in a wetland reclaimed by a 30-year-old seawall and a natural wetland in the Yellow River Delta, China. We also analyzed the differences of their spatial relationships with different plant and soil variables in both wetlands. The results revealed spatial variances in SOC and TN in the seawall-reclaimed wetland at two scales. The smaller scale $(40 \mathrm{~m})$ has reflected the main influences of soil salinity on SOC and TN. The larger scale $(130 \mathrm{~m})$, however, has reflecting the main influences of shrubs on SOC and TN. Variables closely related to SOC (e.g., shrub crown width, percentage of grass cover, and root biomass) showed scale characteristics similar to SOC. The seawall altered patterns of plant distributions and related shrub-grass interactions, thereby affecting SOC and TN. However, in the natural wetland, SOC and TN had only one scale of variance $(90 \mathrm{~m})$, which reflected the main influences of soil salinity. In this wetland, soil salinity determined the spatial patterns of dominant grass patches, and thus soil carbon and nitrogen pools. Scaling methods provide new insights for quantifying the barrier effects of seawall on coastal wetlands and have practical applications for monitoring and assessing coastal wetland degradation after seawall reclamation.

Acknowledgements The work was funded by the National Natural Science Foundation of China (No. 31670471 and 31870468 ).

\section{References}

Bai J, Xiao R, Zhang K, Gao H, Cui B, Liu X (2013) Soil organic carbon as affected by land use in young and old reclaimed regions of a coastal estuary wetland, China. Soil Use Manag 29:57-64

Bi XL, Wenb XH, Yi HP, Wu XQ, Gao M (2014) Succession in soil and vegetation caused by coastal embankment in southern Laizhou Bay, China-flourish or degradation? Ocean Coast Manag 88:1-7

Bulleri F, Chapman MG (2010) The introduction of coastal infrastructure as a driver of change in marine environments. $\mathrm{J}$ Appl Ecol 47:26-35

Chen M, Maie N, Parish K, Jaffé R (2013) Spatial and temporal variability of dissolved organic matter quantity and composition in an oligotrophic subtropical coastal wetland. Biogeochemistry 115:167183

Craine JM, Ballantyne F, Peel M, Zambatis N, Morrow C, Stock WD (2009) Grazing and landscape controls on nitrogen availability across 330 south African savanna sites. Austral Ecol 34:731-740

Davis N, Vanblaricom GR, Dayton PK (1982) Man-made structures on marine-sediments - effects on adjacent benthic communities. Mar Biol 70:295-303

Duarte CM, Middelburg JJ, Caraco N (2005) Major role of marine vegetation on the oceanic carbon cycle. Biogeosciences 2:1-8

Ettema CH, Wardle DA (2002) Spatial soil ecology. Trends Ecol Evol 17: $177-183$ 
Fu X, Liu G, Huang C, Liu Q (2011) Analysis of ecological characteristics of coastal zone in the Yellow River Delta under dam disturbance. J Geo-information Sci 13:797-803 (in Chinese)

He Q, Cui B, Cai Y, Deng J, Sun T, Yang Z (2009) What confines an annual plant to two separate zones along coastal topographic gradients? Hydrobiologia 630:327-340

He Q, Cui BS, Bertness MD, An Y (2012) Testing the importance of plant strategies on facilitation using congeners in a coastal community. Ecology 93:2023-2029

Levin SA (1992) The problem of pattern and scale in ecology. Ecology 73:1943-1967

Liu F, Wu XB, Bai E, Boutton TW, Archer SR (2010) Spatial scaling of ecosystem $\mathrm{C}$ and $\mathrm{N}$ in a subtropical savanna landscape. Glob Chang Biol 16:2213-2223

Liu JT, Rong QQ, Zhao YY (2017) Variations in soil nutrients and salinity caused by tamarisk in the coastal wetland of the Laizhou Bay, China. Ecosphere 8:e01672

Lo Iacono C, Mateo MA, Gracia E, Guasch L, Carbonell R, Serrano L, Serrano O, Danobeitia J (2008) Very high-resolution seismo-acoustic imaging of seagrass meadows (Mediterranean Sea): implications for carbon sink estimates. Geophys Res Lett 35:L18601

Lu QQ, Bai JH, Zhang GL, Zhao QQ, Wu JJ (2018) Spatial and seasonal distribution of carbon, nitrogen, phosphorus, and sulfur and their ecological stoichiometry in wetland soils along a water and salt gradient in the Yellow River Delta, China. Phys Chem Earth 104: 9-17

Ma ZJ, Melville DS, Liu JG, Chen Y, Yang HY, Ren WW, Zhang ZW, Piersma T, Li B (2014) ECOSYSTEMS MANAGEMENT rethinking China's new great wall. Science 346:912-914

McLeod E, Chmura GL, Bouillon S, Salm R, Bjork M, Duarte CM, Lovelock CE, Schlesinger WH, Silliman BR (2011) A blueprint for blue carbon: toward an improved understanding of the role of vegetated coastal habitats in sequestering CO2. Front Ecol Environ 9:552-560

Ottinger M, Kuenzer C, Liu G, Wang S, Dech S (2013) Monitoring land cover dynamics in the Yellow River Delta from 1995 to 2010 based on Landsat 5 TM. Appl Geogr 44:53-68

Perkol-Finkel S, Ferrario F, Nicotera V, Airoldi L (2012) Conservation challenges in urban seascapes: promoting the growth of threatened species on coastal infrastructures. J Appl Ecol 49:1457-1466

Rosenberg MS, Anderson CD (2011) PASSaGE: pattern analysis, spatial statistics and geographic exegesis. Version 2. Methods Ecol Evol 2: 229-232
Rosenzweig C, Solecki WD, Blake R, Bowman M, Faris C, Gornitz V, Horton R, Jacob K, LeBlanc A, Leichenko R, Linkin M, Major D, O'Grady M, Patrick L, Sussman E, Yohe G, Zimmerman R (2011) Developing coastal adaptation to climate change in the New York City infrastructure-shed: process, approach, tools, and strategies. Clim Chang 106:93-127

Saintilan N, Rogers K (2015) Woody plant encroachment of grasslands: a comparison of terrestrial and wetland settings. New Phytol 205: $1062-1070$

Urban DL (2005) Modeling ecological processes across scales. Ecology 86:1996-2006

Wang H, Wang RQ, Yu Y, Mitchell MJ, Zhang LJ (2011) Soil organic carbon of degraded wetlands treated with freshwater in the Yellow River Delta, China. J Environ Manag 92:2628-2633

Wang HQ, Piazza SC, Sharp LA, Stagg CL, Couvillion BR, Steyer GD, McGinnis TE (2017) Determining the spatial variability of wetland soil bulk density, organic matter, and the conversion factor between organic matter and organic carbon across coastal Louisiana, USA. J Coast Res 33:507-517

Wu J (2004) Effects of changing scale on landscape pattern analysis: scaling relations. Landsc Ecol 19:125-138

Xia, J. B., X. M. Zhao, Y. P. Chen, Y. Fang \& Z. G. Zhao (2016) Responses of Water and Salt Variables to Groundwater Levels for Soil Columns Planted with Tamarix chinensis. PLoS One, 11: e0145828

Yang W, Qiao YJ, Li N, Zhao H, Yang R, Leng X, Cheng XL, An SQ (2017) Seawall construction alters soil carbon and nitrogen dynamics and soil microbial biomass in an invasive Spartina alterniflora salt marsh in eastern China. Appl Soil Ecol 110:1-11

Yu J, Li Y, Han G, Zhou D, Fu Y, Guan B, Wang G, Ning K, Wu H, Wang J (2014) The spatial distribution characteristics of soil salinity in coastal zone of the Yellow River Delta. Environ Earth Sci 72:589 599

Yu, J. B., C. Zhan, Y. Z. Li, D. Zhou, Y. Q. Fu, X. J. Chu, Q. H. Xing, G. X. Han, G. M. Wang, B. Guan \& Q. Wang (2016) Distribution of carbon, nitrogen and phosphorus in coastal wetland soil related land use in the Modern Yellow River Delta. Sci Rep, 6:37940

Publisher's note Springer Nature remains neutral with regard to jurisdictional claims in published maps and institutional affiliations. 